\title{
A Review of Cost-Effectiveness Analysis and Model of Hearing Aid Fitting
}

\author{
Soo Hee Oh', Hyungi Chun', Kyoungwon Lee ${ }^{1,2}$, Junghak Lee ${ }^{1,2}$ \\ 'Audiology Institute, Hallym University of Graduate Studies, Seoul, Korea \\ ${ }^{2}$ Department of Audiology, Hallym University of Graduate Studies, Seoul, Korea
}

\begin{abstract}
Purpose: Although many previous literatures investigated various outcomes of hearing aid fitting, a few studies explored the cost-effectiveness of hearing aid fitting and its underlying model. Examining cost effectiveness of hearing aid fitting provides comparative values of hearing aid fitting by measuring the economic gains of hearing aid interventions. The purpose of present study is to understand the cost-related outcomes and benefits of hearing aid uses and provide economic insights of hearing aid interventions. Methods: The study reviewed several literatures related to cost-effectiveness of hearing aid fitting as well as relevant services. In addition, the study proposed an adopted economic model as a future reference of hearing aid fitting in South Korea. Results: There were a few studies evaluating cost-effectiveness of hearing aid fitting and the overall results supported a considerable success with incremental cost-effectiveness of hearing aid intervention. A dynamic patient flow model is particularly useful to simulate ongoing decision problems in the use of hearing aids and to estimate cost-effectiveness of hearing aid intervention. Conclusion: The patient flow model proposed in this study involves various possible transitions of people with hearing complaints in South Korea and it applies to the measurement of cost benefits of hearing aid fitting
\end{abstract}

Key Words: Cost-effectiveness, Hearing aid fitting, Dynamic patient flow model.

Received: November 8, 2016 / Revised: December 28, 2016 / Accepted: December 30, 2016

Correspondence: Junghak Lee, Department of Audiology, Hallym University of Graduate Studies, 405 Yeoksam-ro, Gangnam-gu, Seoul 06198, Korea Tel: +82-2-2051-4950 / Fax: +82-2-3453-6618 / E-mail: leejh@hallym.ac.kr

\section{INTRODUCTION}

In recent years, dramatic growth of geriatric population leads to increase age-related hearing loss (WHO, 2012). A global hearing aids market for the hearing impaired is now expected to reach more than 8,000 million US dollars by 2020 (Research and Markets, 2015). In general, the goal of wearing hearing aids is to improve hearing function, quality of life, and activities and participations in everyday life with increased communication abilities. However, the outcomes, not only related to hearing aid performance (Cox \& Alexander, 1999) but also related to overall perceptions and attitudes (Hosford-Dunn \& Halpern, 2000), vary depending on individual needs, circumstances, and satisfactions.

Hearing aid technologies have made significant progresses in the past decade. Although advanced digital hearing aids offer substantial benefits for hearing aid users with increased comfort, feedback and noise reduction, speech enhancement, and automatic program control (McCormack \& Fortnum, 2013), the im- provements of hearing aid technologies do not always guarantee satisfactory outcomes and high adoption rates.

Previous studies identified several factors influencing on hearing aid outcomes or satisfactions such as 'fit and comfort of the hearing aid' (Bertoli et al., 2009; Gianopoulos et al., 2002; Gopinath et al., 2011; Hartley et al., 2010; Kochkin, 2010; Öberg et al., 2012; Vuorialho et al., 2006), 'hearing aid value/speech clarity' (Bertoli et al., 2009; Hartley et al., 2010; Kochkin, 2010; Vuorialho et al., 2006), 'device factors' (Gianopoulos et al, 2002; Hartley et al., 2010; Kochkin, 2010; Vuorialho et al., 2006), and 'care and maintenance of hearing aid' (Bertoli et al., 2009; Gianopoulos et al, 2002; Kochkin, 2010; Lupsakko et al., 2005; Oberg et al., 2012). Most of them reflect the problems related to poor fits, difficulties of speech understanding in noise, feedback and whistling problems of hearing aids, and handling issues with impaired manual dexterity.

Discrepancies between pre-hearing aid use expectations and post-use outcomes are also significantly associated with overall satisfactions of hearing aid users (Meyer et al., 2014; Wong et 
al., 2009). This result supports the importance of setting realistic expectations for hearing aid benefits, maintaining high level of motivations, and providing continued counseling and education. Interestingly, both experienced (Desjardins \& Doherty, 2009) and inexperienced (Aazh et al., 2015) hearing aid users have reported some of these unsatisfactory results. Above all, Stika \& Ross (2006) demonstrated that less number of hearing aid users fitted hearing aids by audiologists (9.6\%) reported dissatisfaction with hearing aids than the hearing aid users fitted by hearing instrument specialists (21.5\%) emphasizing professional services in hearing aid fitting.

As discussed above, hearing aid fitting is one of key elements to improve hearing aid satisfactions and outcomes. Hearing aid fitting involves adjustment, verification, and orientation procedures with its pre and post fitting stages (Oh \& Lee, 2016). The pre fitting processes emphasize to identify individual hearing functions and their needs and select suitable hearing aids through counseling and hearing evaluation. The post fitting processes focus on enhancing overall performances of hearing aid users and hearing aid adoption with outcome measures and auditory training.

Although hearing aid fitting is generally accepted as the most important part of an intervention to improve hearing aid use, a few studies explored the effect of hearing aid fitting and its underlying model based on cost estimation. Similar to other countries around the world, the hearing aid markets in South Korea are rapidly growing, however, there were no studies to investigate cost-effectiveness and economic model of hearing aid fitting. Examining cost-effectiveness of hearing aid fitting provides comparative values to estimate economic costs and benefits of hearing aid interventions. The purpose of present study is to review previous literatures on the cost-effectiveness of hearing aid fitting to understand the cost-related outcomes and benefits of hearing aid uses and provide economic insights of hearing aid interventions. Accordingly, the study proposes an adopted economic model as a future reference of hearing aid fitting in South Korea.

\section{COSTS OF HEARING AIDS}

Hearing aid prices vary across different hearing aid features including style, type, and technology. According to the National Institutes of Health report (NIH, 2010), the average price of a digital hearing aid is about 1,500 dollars and up to 3,000-5,000 dollars in USA. It was also addressed that also addressed that the price ranges of a single hearing aid are from 800 to 4,000 dollars and these included the cost of the device itself as well as other service fees such as hearing assessment, consultation, fitting times (including post-fitting adjustments), follow-up appointments, and product warranty, typically up to three years (Preferred Hearing Aid Care, 2015). A typical price for a pair of hearing aids is reported to 6,000 dollars and high cost for hearing aids is one of the major barriers to hearing aid ownerships (Abrams \& Kim, 2015; Blustein \& Weinstein, 2016). Blustein \& Weinstein (2016) pointed out two factors leading high hearing aid prices in markets: the noncomperative hearing aid markets, manufacturing $98 \%$ of hearing aids around the worlds by six hearing aid companies and inefficient hearing aid distribution channels.

The insurance coverage for hearing aid fitting varies across countries (Moon et al., 2015) and additional service fees beside hearing aid fitting itself are included in the hearing aid prices (Blustein \& Weinstein, 2016). Hearing aid users often do not fully use the services that they've already lump sum paid (Blustein \& Weinstein, 2016). A recent study addressed high hearing aid prices in South Korea by considering the national income per capita (Moon et al., 2015) and other European countries including Italy, France, and Germany also showed a burden of hearing aid cost for hearing aid ownership (Soren et al., 2013). Although the costs of hearing aids were high in Taiwan, the use of hearing aids was cost-effective when the benefits were measured with quality-adjusted life-years (QALY) gained (Chao \& Chen, 2008).

\section{THE COST-EFFECTIVENESS OF HEARING AID FITTING}

The top reasons for non-use of hearing aids were 'hearing aid value/speech', 'fit and comfort', 'care and maintenance', 'attitude', and 'device factors' (McCormack \& Fortnum, 2013) and these are directly related to hearing aid fitting services with pre and post fitting processes. In addition, the degree of hearing loss and bilateral fitting also influenced on non-regular use of hearing aids (Aazh et al., 2015). Above all, the hearing aid value related to the price is one of the factors influencing on hearing aid satisfactions (Blustein \& Weinstein, 2016; NIH 2010). In this context, investigating cost-effectiveness of hearing aid fitting produces considerable insights to measure effectiveness of hearing aid interventions as a key indicator for successful hearing aid outcomes.

A few previous studies evaluated economic values of hearing aid intervention. Table 1 showed a summary of the studies related to cost-effectiveness of hearing aid fitting and relevant ser- 
Table 1. A summary of the studies related to cost-effectiveness of hearing aid fitting

\begin{tabular}{|c|c|c|c|c|c|c|}
\hline Studies & Country & $\begin{array}{c}\text { Model/study } \\
\text { design }\end{array}$ & Participants & $\begin{array}{c}\text { Utility } \\
\text { instrument }\end{array}$ & Results & $\begin{array}{c}\text { Cost- } \\
\text { effectiveness }\end{array}$ \\
\hline $\begin{array}{l}\text { Boas et al. } \\
(2001)\end{array}$ & Netherland & $\begin{array}{l}\text { Dynamic } \\
\text { model/patient flow } \\
\text { model }\end{array}$ & $\begin{array}{l}\text { Hearing } \\
v \text { impaired } \\
\text { adults aged } \\
\text { over } 18 \text { years }\end{array}$ & $\begin{array}{l}\text { Quality-adjusted } \\
\text { life-years } \\
\text { (QALYs) on } \\
\text { EuroQol }\end{array}$ & $\begin{array}{l}\text { Fitting HA program: } \\
€ 21154 \text { EURO/QALY } \\
\text { Post-purchase counseling HA } \\
\text { program: } € 18,046 \text { EURO/QALY }\end{array}$ & $\begin{array}{l}\text { Sensitive to } \\
\text { the hearing } \\
\text { aid price and } \\
\text { benefits }\end{array}$ \\
\hline $\begin{array}{l}\text { Joore et al. } \\
(2003)\end{array}$ & Netherland & $\begin{array}{l}\text { Dynamic } \\
\text { model/patient flow } \\
\text { model }\end{array}$ & $\begin{array}{l}\text { Hearing } \\
v \text { impaired adults } \\
\text { aged over } 18 \\
\text { years }\end{array}$ & $\begin{array}{l}\text { QALYs on } \\
\text { E EuroQol }\end{array}$ & $\begin{array}{l}\text { Base care outcome: } \\
€ 15,807 \text { EURO/QALY } \\
\text { Costs/hearing-QALY outcomes } \\
€ 1,333-3,889 \text { EURO/QALY } \\
\text { Costs/QALY outcomes } \\
€ 17,996-52,502 \text { EURO/QALY }\end{array}$ & $\begin{array}{l}\text { Cost-effective } \\
\text { in hearing aid } \\
\text { fitting }\end{array}$ \\
\hline $\begin{array}{l}\text { Vuorialho } \\
\text { et al. (2006) }\end{array}$ & Finland & Pre-post design & $\begin{array}{l}\text { Hearing } \\
\text { impaired } \\
\text { adults aged } \\
\text { between } \\
47-87 \text { years }\end{array}$ & $\begin{array}{l}\text { HHIE-S } \\
\text { EQ-5D } \\
\text { EQ-VAS } \\
\text { Interview }\end{array}$ & $\begin{array}{l}\text { Cost for follow-up counseling: } \\
€ 83 \text { EURO per visit } \\
\text { Cost of fitting: } \\
€ 942 \text { EURO per visit: } \\
\text { Increased regular users by } 16 \\
\text { patients } 12 \text { month after fitting } \\
\text { Incremental cost-effectiveness ratio: } \\
€ 508 \text { EURO per one additional } \\
\text { regular use }\end{array}$ & $\begin{array}{l}\text { Cost-effective } \\
\text { in follow-up } \\
\text { counselling }\end{array}$ \\
\hline $\begin{array}{l}\text { Grutters et al. } \\
(2007)\end{array}$ & Netherland & Pre-post design & $\begin{array}{l}\text { Hearing } \\
\text { impaired } \\
\text { adults }\end{array}$ & $\begin{array}{l}\text { EQ-5D } \\
\text { HUI2 } \\
\text { HUI3 }\end{array}$ & $\begin{array}{l}\text { EQ-5D UK tariff: } € 86,866 \text { EURO/ } \\
\text { QALY } \\
\text { EQ-5D Dutch tariff: €47,209 } \\
\text { EURO/QALY } \\
\text { HUI2: €25,377 EURO/QALY } \\
\text { HUI3: €15,811 EURO/QALY }\end{array}$ & $\begin{array}{l}\text { Depend } \\
\text { on utility } \\
\text { measure }\end{array}$ \\
\hline $\begin{array}{l}\text { Chao \& Chen } \\
\text { (2008) }\end{array}$ & Taiwan & $\begin{array}{l}\text { Markov model/ } \\
\text { State-transition } \\
\text { model }\end{array}$ & $\begin{array}{l}\text { Hearing } \\
\text { impaired adults } \\
\text { aged between } \\
50-80 \text { years }\end{array}$ & QALY & $\begin{array}{l}\text { Incremental QALYs: } 1.56 \text { (men)- } \\
0.44 \text { (women) } \\
\text { Incremental cost per QALY with } \\
\text { hearing aids: } \$ 9,702 \text { (men)- } \\
\$ 13,615 \text { (women) }\end{array}$ & $\begin{array}{l}\text { Cost-effective } \\
\text { in hearing aid } \\
\text { uses }\end{array}$ \\
\hline $\begin{array}{l}\text { Baltussen \& } \\
\text { Smith (2009) }\end{array}$ & $\begin{array}{l}\text { Africa and } \\
\text { Asia }\end{array}$ & $\begin{array}{l}\text { WHO-CHOICE } \\
\text { cost-effectiveness } \\
\text { analysis/over } 10 \\
\text { years }\end{array}$ & $\begin{array}{l}\text { Adults and } \\
\text { children }\end{array}$ & $\begin{array}{l}\text { Disability- } \\
\text { adjusted life } \\
\text { years (DALYs) }\end{array}$ & $\begin{array}{l}\text { Incremental cost effective ratio } \\
\text { for passive screening } \\
\text { intervention: ranging from I\$ } \\
\text { 998/DALY (Africa) to I\$ } 1,053 \text { / } \\
\text { DALY (Asia) } \\
\text { Incremental cost effective ratio for } \\
\text { all screening interventions: } \\
\text { ranging from I\$ 1,070/DALY } \\
\text { (Africa) to I\$ 1,472/DALY (Asia) }\end{array}$ & $\begin{array}{l}\text { Cost-effective } \\
\text { in hearing } \\
\text { screening and } \\
\text { hearing aid } \\
\text { provision }\end{array}$ \\
\hline $\begin{array}{l}\text { Rob et al. } \\
(2009)\end{array}$ & India & $\begin{array}{l}\text { Observational } \\
\text { study design }\end{array}$ & $\begin{array}{l}\text { Patients from } \\
\text { three different } \\
\text { programs with } \\
\text { or without } \\
\text { hearing } \\
\text { impaired }\end{array}$ & DALYs & $\begin{array}{l}\text { Cost per DALY averted: } \$ 900 \text { at } \\
\text { active secondary care lever, } \$ 720 \\
\text { at passive tertiary care level }\end{array}$ & $\begin{array}{l}\text { Cost-effective } \\
\text { in hearing } \\
\text { screening and } \\
\text { delivery of } \\
\text { hearing aid } \\
\text { uses }\end{array}$ \\
\hline
\end{tabular}

HHIE-S: hearing handicap inventory for the elderly screening version, EQ-5D: EuroQol five dimensions questionnaire, EQ-VAS: EuroQol-visual analogue scales, HUI2: health utilities index mark 2, HUI3: health utilities index mark 3 
vices. Cost utility analysis was used to estimate incremental benefits after hearing aid fitting or relevant services with considerable variation in the choice of a utility instrument. Overall, the results provided some evidences of cost-effectiveness of hearing aid fitting and relevant services involving screening and follow up counseling with different magnitudes of the utility gains across the studies. In addition, the choice of utility instrument is a key factor to determine cost-effectiveness of hearing aid fitting. For instance, Chao \& Chen (2008) showed different Incremental QALYs between men (1.56) and women (0.44) by supporting different magnitudes of the utility gains. On the other hand, Grutters et al. (2007) identified cost-effectiveness with only the health utilities index mark 3 among the utility instruments used in their study. Other study (Vuorialho et al., 2006) evaluating the effect of follow up counseling showed that a number of regular users were increased by 16 clients after follow-up counseling and the expense of follow-up counseling at home was only an $8.8 \%$ increment over the calculated cost of fitting a hearing aid. In addition, hearing screening following hearing aid provisions was also cost-effective (Baltussen \& Smith, 2009; Rob et al., 2009).

\section{AN ADOPTED COST-EFFECTIVENESS MODEL OF HEARING AID FITTING IN SOUTH KOREA}

Joore et al. (2003) analyzed cost-effectiveness of hearing aid fitting in the Netherlands based on a dynamic patient flow model (Boas et al., 2001). The model was used to estimate economic costs for hearing aid fitting in Netherland considering transitions occurred over time at various health care divisions including audiological centers and medical centers. The patient flow model was constructed with the flow diagrams of hearing aid fitting on patient sides and was incorporated into a cohort study enabling them to make comparisons across different age groups.

Figure 1 shows the dynamic patient flow model focusing on hearing aid fitting in South Korea adopted from the model reported by Joore et al. (2003). The model involves three patient groups across different transition stages: non-hearing aid users with hearing complaints, satisfied hearing aid users and dissatisfied hearing aid users. Non-hearing aid users with hearing complaints visit hearing aid professionals or medical professionals to consult and assess their hearing problems and needs during the pre-fitting stage. A referral to medical professionals is necessary if clients have any problems requiring medical treatments and cares. Medical professionals also refer clients with

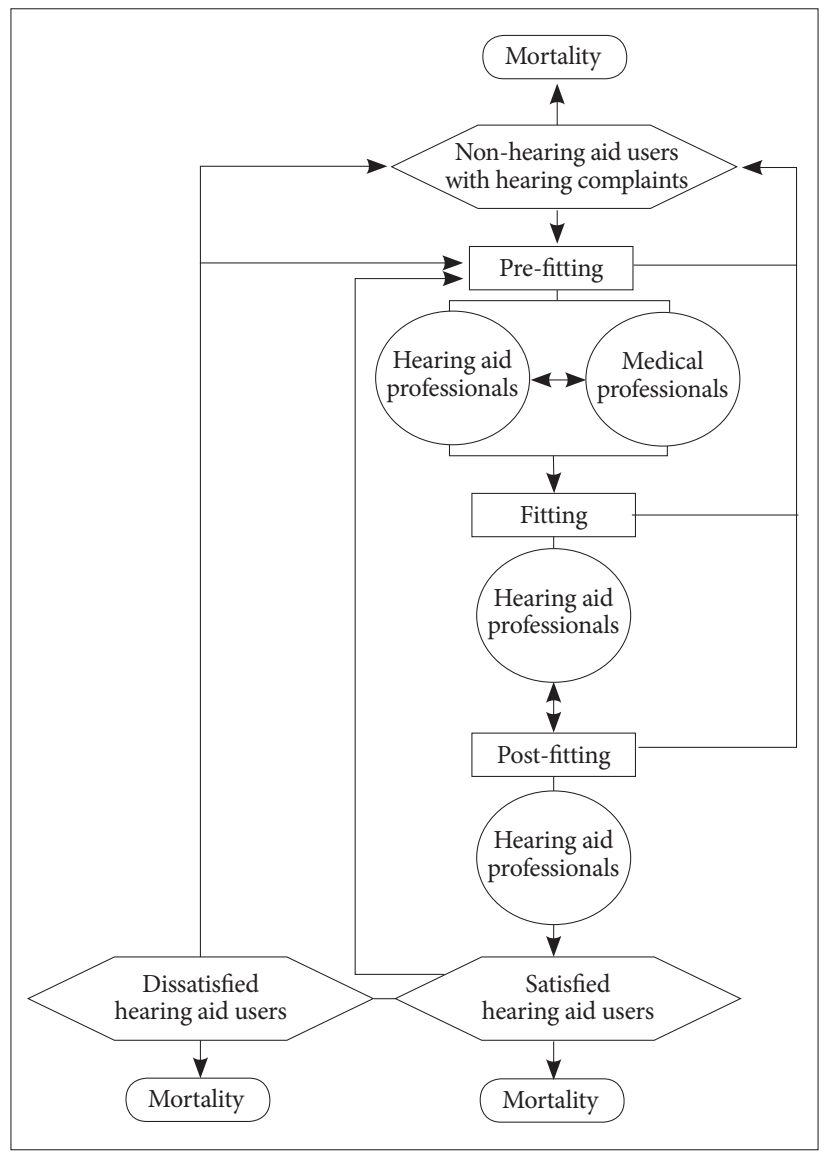

Figure 1. A cost-effectiveness model of hearing aid fitting in South Korea based on the dynamic patient flow model reported by Joore et al. (2003).

hearing impairments to hearing aid professionals after medical treatments or whenever professional hearing aid services are needed. After hearing aid professionals fit individuals' hearing aids at the fitting stage, clients revisit hearing aid professionals for follow-up service. Fitting and post-fitting stages may be repeated depending on individuals' satisfactions and outcomes. Satisfied hearing aid users may use hearing aids regularly and revisit hearing aid professionals for routine check-up or various individual needs. Unsatisfied hearing aid users may revisit hearing aid professionals to resolve unsatisfactory factors. Currently, partial coverage for the fees related to hearing aids and hearing rehabilitation is provided by the South Korean government for some people who meet eligibility criteria. This adopted model involves various possible transitions of people with hearing complaints and is applicable to measure cost benefits of hearing aid fitting in South Korea as a future reference model. 


\section{DISCUSSIONS}

The present study reviewed previous literatures related to cost-effectiveness of hearing aid fitting to provide baseline information estimating economic benefits of hearing aid interventions and developing a model of hearing aid fitting in South Korea. We analyzed seven literatures evaluating cost-effectiveness of hearing aid fitting and overall results supported a considerable success with incremental cost-effectiveness of hearing aid intervention.

Although cost issues are important for hearing aid intervention, it is not easy to exam and conduct the cost-effective analysis. In this context, Ali et al. (2008) explained some drawbacks of cost-effectiveness studies in hearing aid interventions such as inappropriate sample size, lacked of appropriate control groups, differences in interventions and methods, control for missing patients, and so on.

A dynamic patient flow model introduced in this study is particularly useful to simulate ongoing decision problems in the use of hearing aids and estimate cost-effectiveness of hearing aid intervention. The transition stages of hearing aid interventions may vary across countries. For instance, Netherland showed four major transitions and four main service providers including audiologists, hearing aid dispensers, general practitioners, and ear, nose, and throat doctors (Joore et al., 2003). The adopted model proposed by the authors of this study includes two main categories of service providers consisting of hearing aid professionals and medical professionals. Audiologist and hearing aid dispensers will be included in the hearing aid professional category and general practitioners and ENT doctors will be included in the medical professional category of this model. Compared to the increased hearing aid population and relevant service providers, there is a lack of guidelines and models to support cost-effectiveness and service delivery in South Korea. Specifically, economic values in hearing aid fitting should be estimated by considering patients ongoing decision processes and individual satisfactions. This also will be applicable to price calculations of hearing aid and relevant services provided.

In addition, Joore et al. (2003) speculated variables considerably influencing on the costs/QALY outcome such as hearing aid prices and dissatisfied hearing aid users. However, results of the sensitivity analysis in their study supported that high hearing aid prices do not influence on the health related quality of life benefits assuming additional benefits of using expensive hearing aids with improved quality in real life. Probability of changing into unsatisfied hearing aid users is also considered to influence on cost-effectiveness of hearing aid fitting. The adopted model proposed in this study assumed that the services provided during pre-fitting, fitting, and post-fitting substantially influence on satisfactions of hearing aids. Changes of hearing aid intervention policy or individual transitions should be considered to reduce a probability of unsatisfactory outcomes with hearing aids. Accordingly, other studies showed cost-effectiveness of follow up counseling (Boas et al., 2001; Vuorialho et al., 2006) and hearing screening (Baltussen \& Smith, 2009; Rob et al., 2009). These indicate that providing relevant services in pre and post stages of hearing aid fitting is cost-effective and may play an important role to reduce unsatisfied hearing aid users. Overall, this study suggests that the economic model of hearing aid intervention suitable for South Korea is necessary to calculate economic costs of hearing aid interventions consisting of pre-fitting, fitting, and post-fitting and it will also applicable to improve health care policies and services for the hearing impaired.

\section{Acknowledgments}

This work was supported by a grant from the Korean Ministry of Trade, Industry \& Energy, Project No. 10049456.

\section{REFERENCES}

Aazh, H., Prasher, D., Nanchahal, K., \& Moore, B. C. (2015). Hearing-aid use and its determinants in the UK National Health Service: A crosssectional study at the Royal Surrey County Hospital. International Journal of Audiology, 54(3), 152-161.

Abrams, H. B. \& Kihm, J. (2015). An introduction to MarkeTrak IX: A new baseline for the hearing aid market. Hearing Review, 22(6), 16.

Ali, W., Suebwongpat, A., \& Weston, A. (2008). The effectiveness of digital hearing aids and assistive listening devices for adults with hearing loss: A systematic review of the literature. HSAC Report, 1(4). http:// www.healthsac.net/downloads/publications/HSAC03\%20Hearing\% 20Aids\%20081008\%20FINAL.pdf.

Baltussen, R. M. P. M. \& Smith, A. (2009). Cost-effectiveness of selected interventions for hearing impairment in Africa and Asia: A mathematical modelling approach. International Journal of Audiology, 48(3), 144-158.

Bertoli, S., Staehelin, K., Zemp, E., Schindler, C., Bodmer, D., \& Probst, R. (2009). Survey on hearing aid use and satisfaction in Switzerland and their determinants. International Journal of Audiology, 48(4), 183195.

Blustein, J. \& Weinstein, B. E. (2016). Opening the market for lower cost hearing aids: Regulatory change can improve the health of older Americans. American Journal of Public Health, 106(6), 1032-1035.

Boas, G., Van Der Stel, H., Peters, H., Joore, M., \& Anteunis, L. (2001). Dynamic modeling in medical technology assessment. Fitting hearing aids in The Netherlands. International Journal of Technology Assessment in Health Care, 17(4), 618-625.

Chao, T. K. \& Chen, T. H. H. (2008). Cost-effectiveness of hearing aids in the hearing-impaired elderly: A probabilistic approach. Otology and Neurotology, 29(6), 776-783.

Cox, R. M. \& Alexander, G. C. (1999). Measuring Satisfaction with Am- 
plification in Daily Life: The SADL scale. Ear and Hearing, 20(4), 306320.

Desjardins, J. L. \& Doherty, K. A. (2009). Do experienced hearing aid users know how to use their hearing aids correctly? American Journal of Audiology, 18(1), 69-76.

Preferred Hearing Aid Care (2015, May 21). Hearing aid prices. Retrieved from https://www.preferredhearingcare.net/news/2015/5/21/hearingaid-prices.

Gianopoulos, I., Stephens, D., \& Davis, A. (2002). Follow up of people fitted with hearing aids after adult hearing screening: The need for support after fitting. British Medical Journal, 325(7362), 471.

Gopinath, B., Schneider, J., Hartley, D., Teber, E., McMahon, C. M., Leeder, S. R., et al. (2011). Incidence and predictors of hearing aid use and ownership among older adults with hearing loss. Annals of Epidemiology, 21(7), 497-506.

Grutters, J. P., Joore, M. A., van der Horst, F., Verschuure, H., Dreschler, W. A., \& Anteunis, L. J. (2007). Choosing between measures: Comparison of EQ-5D, HUI2 and HUI3 in persons with hearing complaints. Quality of Life Research, 16(8), 1439-1449.

Hartley, D., Rochtchina, E., Newall, P., Golding, M., \& Mitchell, P. (2010). Use of hearing aids and assistive listening devices in an older Australian population. Journal of the American Academy of Audiology, 21(10), 642-653.

Hosford-Dunn, H. \& Halpern, J. (2000). Clinical application of the satisfaction with amplification in daily life scale in private practice I: Statistical, content, and factorial validity. Journal of the American Academy of Audiology, 11(10), 523-539.

Joore, M. A., van der Stel, H., Peters, H. J., Boas, G. M., \& Anteunis, L. J. (2003). The cost-effectiveness of hearing-aid fitting in the Netherlands. Archives of Otolaryngology-Head and Neck Surgery, 129(3), 297-304.

Kochkin, S. (2010). MarkeTrak VIII: Consumer satisfaction with hearing aids is slowly increasing. The Hearing Journal, 63(1), 19-20.

Lupsakko, T. A., Kautiainen, H. J., \& Sulkava, R. (2005). The non-use of hearing aids in people aged 75 years and over in the city of Kuopio in Finland. European Archives of Oto-Rhino-Laryngology and Head and Neck, 262(3), 165-169.

McCormack, A. \& Fortnum, H. (2013). Why do people fitted with hearing aids not wear them? International Journal of Audiology, 52(5), 360-368.

Meyer, C., Hickson, L., Khan, A., \& Walker, D. (2014). What is important for hearing aid satisfaction? Application of the expectancy-disconfirmation model. Journal of the American Academy of Audiology, 25(7),
644-655.

Moon, I. J., Baek, S. Y., \& Cho, Y. S. (2015). Hearing aid use and associated factors in South Korea. Medicine, 94(42), e1580.

National Institutes of Health (NIH). (2010, October). Fact sheet-Hearing aids. Retrieved from https://report.nih.gov/nihfactsheets/viewfactsheet.asp $x$ ? csid $=95$.

Öberg, M., Marcusson, J., Nägga, K., \& Wressle, E. (2012). Hearing difficulties, uptake, and outcomes of hearing aids in people 85 years of age. International Journal of Audiology, 51(2), 108-115.

Oh, S. H. \& Lee, J. (2016). General framework of hearing aid fitting management. Journal of Audiology and Otology, 20(1), 1-7.

Research and Markets. (2015). Hearing aids market by Product (ReceiverIn-The-Ear, Behind-The-Ear, In-The-Ear, Canal Hearing Aids, Cochlear Implants, Bone Anchored Systems), Hearing loss (Sensorineural, Conductive), End-User (Adults, Pediatrics)-Global Forecasts to 2020. Retrieved from http://www.researchandmarkets.com/research/ x62147/hearing_aids.

Rob, B., Monica, P., Balraj, A., Job, A., Norman, G., \& Joseph, A. (2009). Costs and health effects of screening and delivery of hearing aids in Tamil Nadu, India: An observational study. BioMed Central Public Health, 9, 135.

Soren, H., Stefan, R., \& Christian, E. (2013). EuroTrak + Japan Trak 2012: Societal and personal benefits of hearing rehabilitation with hearing aids. Hearing review. Retrieved from http://www.hearingreview.com/ 2013/03/eurotrak-japantrak-2012-societal-and-personal-benefits-ofhearing-rehabilitation-with-hearing-aids/.

Stika, C. J. \& Ross, M. (2006). Hearing aid services and satisfaction: The consumer viewpoint. Retrieved from http://www.audiologist.org/_resources/documents/publications/marketing/Hearing_aid_services_ and_satisfaction.pdf.

Vuorialho, A., Karinen, P., \& Sorri, M. (2006). Counselling of hearing aid users is highly cost-effective. European Archives of Oto-Rhino-Laryngology and Head and Neck, 263(11), 988-995.

Wong, L. L., Hickson, L., \& McPherson, B. (2009). Satisfaction with hearing aids: A consumer research perspective. International Journal of Audiology, 48(7), 405-427.

World Health Organization (WHO). (2012). Hearing loss in persons 65 years and older based on WHO global estimates on prevalence of hearing loss. Retrieved from http://www.who.int/pbd/deafness/news/GE_ 65years.pdf. 